\title{
DIVERSIDADE BACTERIANA EM SUPERFÍCIES DE RESTAURANTES DE PALMAS-TO
}

BACTERIAL DIVERSITY ON SURFACES OF PALMAS-TO
RESTAURANTS

\author{
Lucas Campos Fonseca', Guilherme Henrique Moreira Azevedo', Renan
} Miranda Sanatana ${ }^{1}$, Anderson Barbosa Baptista ${ }^{2}$.

\begin{abstract}
RESUMO
A urbanização, industrialização, profissionalização das mulheres e redução do tempo para preparação e / ou consumo de alimentos implicaram em um maior consumo de refeições extra domicílio. A contaminação cruzada em alimentos pode representar um risco às pessoas por aumentar a chance de desenvolver diversas patologias gastrointestinais. O objetivo desse estudo foi avaliar as condições higiênicas sanitárias de cinco restaurantes de Palmas. As amostras foram coletadas entre abril de 2015 a fevereiro de 2016, na cidade de Palmas, Tocantins, de 5 restaurantes, em superfícies de utensílios, bancadas, bandejas, copos, tábuas e esponjas. Coletou-se em swab estéril por fricção e meio BHI para transporte e crescimento. Posteriormente foram submetidos a provas bioquímicas para diferenciação. Foram coletadas 50 amostras e encontradas onze cepas de bactérias. As mais prevalentes foram Sthaphylococcus sp (54,8\%) e Klebsiella sp. (29\%). Os objetos que apresentaram maior contaminação foram as bancadas de preparação $(18,6 \%)$, as tábuas $(13,6 \%)$ e as esponjas (11,8\%). A partir dos dados apresentados no estudo fica evidente a necessidade de melhorias nos processos higiênicosanitário dos restaurantes, com a finalidade de diminuir a contaminação, a disseminação de cepas possivelmente virulentas e as infecções gastrointestinais.

Palavras-chave: microorganismos, restaurante, contaminação, utensílios.
\end{abstract}

Citação: Fonseca LC, Azevedo GHM, Sanatana RM, Baptista AB (2019) Diversidade bacteriana em superfícies de restaurantes de Palmas-TO. Revista de Patologia do Tocantins, 6(2): 10-14.

Instituição: ${ }^{1}$ Acadêmico(a) de Medicina, Universidade Federal do Tocantins, Tocantins, Brasil; ${ }^{2}$ Professor doutor, docente do curso de Medicina, Universidade Federal do Tocantins, Tocantins, Brasil.

Autor correspondente: Lucas Campos Fonseca; lucascamposnf@gmail.com

Editor: Guedes V. R. Medicina, Universidade Federal do Tocantins, Brasil.

Publicado: 09 de junho de 2019.

Direitos Autorais: (c) 2019 Fonseca et al. Este é um artigo de acesso aberto que permite o uso, a distribuição e a reprodução sem restrições em qualquer meio, desde que o autor original e a fonte sejam creditados.

Conflito de interesses: os autores declararam que não existem conflitos de interesses.

\begin{abstract}
Urbanization, industrialization, professionalization of women and reduction of the pace of preparation and / or consumption of food have led to a greater consumption of extra-household meals. Cross-contamination in food may be increasing the chance of increasing the chances of gastrointestinal. The objective of the study was to evaluate the hygienic sanitary conditions of five restaurants in Palmas. The waters were collected between April 2015 and February 2016, in the city of Palmas, Tocantins, of 5 restaurants, in planks, trays, cups, boards and sponges. It was collected on sterile friction swab and $\mathrm{BHI}$ medium for transport and growth. Subsequently, they were submitted to a biochemical test for differentiation. Fifty samples were collected and found in bacterial strains. The most prevalent were Staphylococcus sp (54.8\%) and Klebsiella sp. (29\%). The problems of higher contamination were preparation benches $(18.6 \%)$, boards $(13.6 \%)$ and sponges (11.8\%). From the data presented the analysis of hygiene and food consumption processes, with the purpose of reducing contamination, health dissemination and gastrointestinal infections.

Keywords: microorganisms, restaurants, contamination, utensils.
\end{abstract}




\section{INTRODUÇÃO}

$\mathrm{Na}$ sociedade contemporânea a urbanização, industrialização, profissionalização das mulheres e redução do tempo para preparação e / ou consumo de alimentos, entre outros fatores implicaram em um maior consumo de diário de refeições extra domicílio ${ }^{1,2}$. Com esse cenário, além da discussão no tocante à qualidade nutricional dos alimentos servidos nos restaurantes, é importante atentar-se para a higiene do preparo e para a adequação do ambiente onde essas refeições são preparadas para evitar diversas patologias gastrointestinais que podem ser veiculadas por alimentos contaminados ${ }^{3}$.

A contaminação cruzada é um termo que faz referencia à transferência de microrganismos de um item contaminado para um produto não contaminado, na alimentação esse fato pode representar um risco ao ser humano nas infecções gastrointestinais ${ }^{4}$. A evidência científica vem de estudos de epidemiologia realizados na Europa, América do Norte, Austrália e Nova Zelândia que chegam à conclusão que uma grande quantidade de infecções do trato gastrointestinal é atribuível a práticas impróprias na preparação de alimentos ${ }^{5}$. Várias fontes contribuem para a presença de patógenos no alimento do consumidor final como superfícies contaminadas, mão de funcionários mal higienizadas e os próprios alimentos in natura ${ }^{6}$. O contato posterior dessas fontes com outras superfícies da cozinha foi documentado como uma possível fonte para transferência desses patógenos para essas superfícies, possibilitando uma importante fonte de contaminação cruzada. Uma possível forma de minimizar seria a utilização de tábuas de corte separadas para preparar carne e produtos in natura, a limpeza adequada do ambiente de trabalho, a higienização dos pacientes e o correto descarte dos lixos produzidos 7,8 .

Uma das principais consequências da contaminação de alimentos por bactérias é o acometimento com gastroenterites. As diarreias agudas por causas bacterianas são menos comuns, mas são responsáveis por casos mais graves de diarreia infecciosa do que outras etiologias, nesses casos um patógeno bacteriano foi identificado em $87 \%$ dos $\operatorname{casos}^{8}$.

Entre essas causas bacterianas graves, Salmonella não tifoide e Campylobacter sp são as causas mais comuns nos Estados Unidos. A taxa de incidência por 100.000 pessoas em 2016 foi estimada pelo programa de vigilância ativa controlada pelo Centers for Disease Control and Prevention, Food Net, com resultados como segue:

Salmonella (15.4\%),Campylobacter (11.8\%), Shigella (4.6\%), E. coli (2.8\%), Vibrio $(0.45 \%)^{9}$. A diarreia infecciosa está entre as principais causas de doença em todo o mundo e está associada a 1,5 a 2,5 milhões de mortes por ano ${ }^{10}$. No Brasil os dados sobre a taxa de incidência da diarreia aguda não são muito recentes. Entre 2000 e 2011 foram notificados 33 milhões de casos de diarreia associados a alimentos contaminados, a maioria em menores de um ano de idade ${ }^{11,12}$.

Estudos sobre a diversidade bacteriana em restaurantes trazem a $E$. coli como a mais frequente, encontrado em $29,7 \%$ do total de amostras, seguida de Serratia sp. e Enterobacter aerogenes. Detectou-se, ainda, a presença de Klebsiella pneumoniae, K. oxytoca, Citrobacter spp., Arizona sp, E. cloacae, E, E. sakazakii, Hafnia alvei e Serratia sp., Salmonella, A maior parte das amostras apresentaram uma ou duas espécies ${ }^{13,14}$.

O objetivo desse estudo foi avaliar as condições higiênico sanitárias de cinco restaurantes de Palmas que possuem as mesmas características funcionais e estruturais, escolhidos de forma aleatória, utilizando como parâmetros as superfícies dos utensílios e bancadas.

\section{MATERIAIS E MÉTODOS}

\section{LOCAL}

As amostras foram coletadas entre abril de 2015 a fevereiro de 2016, na cidade de Palmas, Tocantins, no plano Diretor Sul, de 5 restaurantes escolhidos pelas características estruturais e de serviços semelhantes, de forma aleatória.

\section{OBJETO DA COLETA}

Utensílios, bancadas, bandejas, copos, tábuas e esponjas com as mesmas características entre os restaurantes, utilizados exclusivamente no preparo e/ou manipulação dos alimentos.

\section{MÉTODO}

Para a coleta de possíveis microrganismos presente em utensílios ou bancadas utilizou-se swab estéril friccionandoo em cada material e em seguida colocando em ágar $\mathrm{BHI}$ (Infusão cérebro-coração) para o transporte e crescimento, e transportados ao laboratório de microbiologia da UFT, campus de Palmas. Em todos os procedimentos utilizaram-se luvas estéreis, máscaras e touca.

Os tubos com BHI e swab foram acondicionados a $37^{\circ} \mathrm{C}$ em estufa bacteriológica por 24 a 48 horas. Uma alíquota de 10 uL de cada tubo foi repicada em meios agar Mac Conkey, agar Mueller Hinton, agar Sal Manitol, agar Verde Brilhante e agar SS (Salmonella-Shigella). As enterobactérias foram submetidas às provas bioquímicas TSI (tríplice açúcar inositol), SIM (Sulfeto, indol, motilidade), Citrato de Simmons, Lisina, Fenilalanina, Ornitina e malonato e para confirmação foram usados meio Rugai Modificado e Bactray I e II. Para a identificação de Cocos gram positivos utilizaram-se provas da catalase e coagulase.

\section{RESULTADOS E DISCUSSÃO}

Esse estudo demonstra a qualidade higiênico sanitária de alguns estabelecimentos que trabalham com alimentos e chama a atenção nos hábitos de má higienização de objetos utilizados no preparo ou para a alimentação. A partir do estudo é possível observar que a desinformação atrelada ao despreparo dos funcionários levam a contaminação gerando possibilidade de desenvolvimento de patologias gastrointestinais e/ou veiculação dos microrganismos para outros ambientes.

Os microrganismos que estão presentes em um alimento constituem sua microbiota, esses são adquiridos por processos como produção, distribuição, armazenamento e preparo para o consumidor final ${ }^{15}$. Dentro desse espectro várias são as medidas nas diferentes etapas que poderiam diminuir a contaminação e uma possível infecção do consumidor final. A ênfase da pesquisa esta na preparação 
final, isto é, no manejo e nos utensílios presentes nos restaurantes do estilo self-service ${ }^{16}$.

Nesse estudo foram coletadas 50 amostras. Foram isoladas onze cepas bacterianas. Em alguns casos foram isolados mais de uma espécie em uma mesma superfície. As espécies mais prevalentes foram Sthaphylococcus sp $(54,8 \%) e$ Klebsiella sp (29\%), respectivamente. Em quatorze amostras o resultado foi negativo. Em apenas uma amostra foi isolada cepas de Escherichia coli, espécie com sorotipos importante causadores de infecções gastrointestinais (Tabela 1 ). emergem como patógenos e muitas vezes resistentes aos antimicrobianos, um grande problema de saúde pública ${ }^{25}$.

A maioria das cepas encontradas corresponde a coliformes fecais e não patógenos intestinais propriamente ditos (Figura 1). O grupo coliforme pode ser definido como todas as bactérias aeróbias ou anaeróbias facultativas, gramnegativas, não esporuladas, na forma de bastonete que fermentam a lactose com formação de gás dentro de $48 \mathrm{~h}$ a 35 으 ${ }^{26}$. Seus principais representantes

\begin{tabular}{|c|c|c|c|c|c|}
\hline & Restaurante 1 & Restaurante 2 & Restaurante 3 & Restaurante 4 & Restaurante 5 \\
\hline Bancada de preparação & $\begin{array}{l}\text { Acinetobacter baummanii, Klebsiella } \\
\text {,S. aureus } \quad a\end{array}$ & 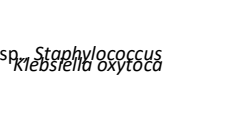 & $\begin{array}{l}\text { Staphylococcus coagulase } \\
\text { negativo }\end{array}$ & $\begin{array}{l}\text { Staphylococcus coagulase } \\
\text { negativo } \\
\text { Proteus sp } \\
\text { Serratia sp.; }\end{array}$ & $\begin{array}{l}\text { Acinetobacter sp; } \\
\text { Citrobacter Freundii }\end{array}$ \\
\hline Pratos & $\begin{array}{l}\text { Klebsiella sp., Staphylococcus } \\
\text { coagulase negativa }\end{array}$ & $\begin{array}{l}\text { Staphylococcus coagulase } \\
\text { negativa }\end{array}$ & Negativo & Negativo & Negativo \\
\hline Esponja & $\begin{array}{l}\text { Sthaphylococos aureus; } \\
\text { Klebsiella oxytoca }\end{array}$ & Klebsiella oxytoca & $\begin{array}{l}\text { Staphylococcus coagulase } \\
\text { negativo } \\
\text {; }\end{array}$ & $\begin{array}{l}\text { Staphylococcus coagulase } \\
\text { negativo } \\
; \\
\text { Serratia sp }\end{array}$ & Citrobacter freundii \\
\hline Bancada da Pia & Staphylococcus aureus; & Kleibsiella oxytoca & Klebsiella oxytoca & $\begin{array}{l}\text { Staphylococcus coagulase } \\
\text { negativo } \\
\text {; Acinetobacter sp }\end{array}$ & $\begin{array}{l}\text { Citrobacter freundi; } \\
\text { Acinetobacter sp }\end{array}$ \\
\hline Utensílio de saladas & Acinetobacter sp; & Citrobacter sp. & $\begin{array}{l}\text { Klebsiella oxytoca ; } \\
\text { Staphylococcus coagulase } \\
\text { negativo }\end{array}$ & $\begin{array}{l}\text { Staphylococcus coagulase } \\
\text { negativo; Serratia sp }\end{array}$ & Citrobacter freundii \\
\hline $\begin{array}{l}\text { Armazenador de } \\
\text { talheres }\end{array}$ & $\begin{array}{l}\text { Staphylococcus coagulase } \\
\text { negativo } \\
\text {; Serratia sp. }\end{array}$ & Serratia sp & $\begin{array}{l}\text { Staphylococcus coagulase } \\
\text { negativo }\end{array}$ & Negativo & $\begin{array}{l}\text { Acinetobacter sp; Citrobacter } \\
\text { freundii }\end{array}$ \\
\hline Bancada de saladas & $\begin{array}{l}\text { Klebsiella sp.;Serratia sp.; } \\
\text { Staphylococcus coagulase } \\
\text { negativo } \\
\text {. }\end{array}$ & Negativo & Negativo & Negativo & Negativo \\
\hline Tábua & Negativo & Escherichia coli & $\begin{array}{l}\text { Enterobacter aerogenes; } \\
\text { Enterobacter cloacae e } \\
\text { Staphylococcus coagulase } \\
\text { negativo }\end{array}$ & $\begin{array}{l}\text { Staphylococcus coagulase } \\
\text { negativo } \\
\text {; Acinetobacter sp }\end{array}$ & $\begin{array}{l}\text { Acinetobacter sp; Citrobacter } \\
\text { freundii }\end{array}$ \\
\hline Bandeja & $\begin{array}{l}\text { Staphylococcus Aureus; Klebsiella } \\
\text { pneumoniae; Enterobacter } \\
\text { clocae }\end{array}$ & Negativo & Enterobacter $\mathrm{sp}$ & $\begin{array}{l}\text { Staphylococcus coagulase } \\
\text { negativo }\end{array}$ & Negativa \\
\hline
\end{tabular}

Tabela 1. Espécies bacterianas isoladas em objetos utilizados no preparado de alimentos em 5 restaurantes de Palmas-TO

As superfícies que apresentaram maior contaminação foram as bancadas de preparação $(18,6 \%)$, as tábuas $(13,6 \%)$ e as esponjas $(11,8 \%)$, o que sugere que muitas vezes a contaminação acontece durante o processo de assepsia e durante o processo de preparação dos alimentos. É importante salientar que essas bancadas e tábuas podem servir para a preparação de alimentos que são servidos cozidos e aqueles que são servidos crus, sem a devida desinfecção facilitando assim uma contaminação cruzada. A desinfecção utilizando etanol a $70 \%$ e/ou água sanitária podem ser bons aliados ao processo de higienização ${ }^{10}$.

A bactéria mais prevalente nos estudos foi o Staphylococcus coagulase negativo que é componente da microbiota residente da pele de seres humanos e se acumula principalmente em áreas com maior número de glândulas sebáceas como a mão ${ }^{24}$. Sua presença em grande quantidade em membros facilita a disseminação principalmente pelo manuseio constante de objetos e de alimentos. Um grande problema é que algumas dessas bactérias antes comensais são: Escherichia, Aerobacter, Citrobacter, Klebsiela e a Serratia (artigo 28). Alguns coliformes fecais são patogênicos entretanto sua presença é um indicador de contaminação fecal e um marcador da probabilidade de que patógenos entéricos estejam presentes ${ }^{27}$

As normas da ANVISA (agência nacional de vigilância sanitária) apresentada aos estabelecimentos gastronômicos são muito claras ao tratar da necessidade de limpeza do ambiente, higienização do funcionário, cuidados com a água e uma organização adequada do lixo produzido para evitar que ocorra a contaminação do alimento.

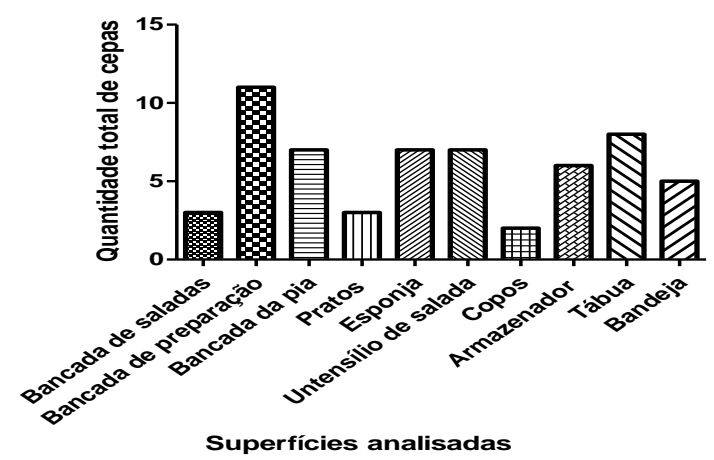




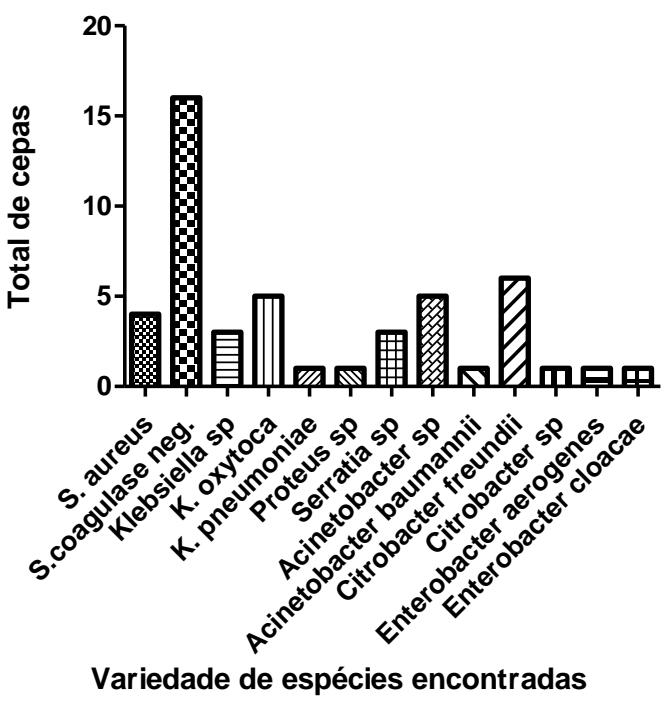

Figura 1. Quantidade total de cepas em superfícies de objetos utilizados no processamento de alimentos em 5 restaurantes de Palmas (A); Diversidade de espécies bacterianas identificadas em todos os restaurantes (B).

Algumas recomendações poderiam diminuir substancialmente essa contaminação. Além daqueles preconizados pela ANVISA e pela ABRASEL (Associação brasileira de bares e restaurantes), como a higiene de funcionários, o manejo correto de alimentos, a preocupação com a limpeza de caixa da água outras seriam vitais. As recomendações aqui citadas dão ênfase em pontos obtidos pelo estudo. Nesse sentido, as bancadas de preparação e as tábuas se mostraram os locais de maior contaminação e uma possível forma de diminuir seria a desinfecção das superfícies entre o manuseio de alimentos diferentes e o não compartilhamento de utensílios entre alimentos, um exemplo e não usar uma mesma faca para cortar diversos alimentos e caso fosse fazer realizar uma desinfecção prévia com água e sabão ou hipoclorito de sódio ${ }^{18}$. Com relação ao segundo material mais contaminado que são as esponjas de limpeza um estudo comprovou que a imersão das esponjas em água fervente trás melhores resultados que a desinfecção com hipoclorito de sódio, além da troca após no máximo um mês de uso ${ }^{10}$

A contaminação de utensílios e uma posterior contaminação do alimento pode provocar a ingestão de bactérias em níveis patológicos, causando infecções gastrointestinais. Essas infecções aparecem como uma das mais comuns patologias associados à morbimortalidade ao ser humano ${ }^{14}$. Comumente são causados por parasitas intestinais, vírus e bactérias. Cerca de $90 \%$ dessas infecções são causadas por vírus, os restantes $10 \%$ se dividem entre parasitas, como helmintos e protozoários, e bactérias ${ }^{20}$. Entretanto a infecção por bactérias sem dúvidas possui maior morbimortalidade ${ }^{21}$. Os principais agentes bacterianos relacionados com gastroenterites incluem os gêneros Salmonella, Shigella, Escherichia, Staphylococcus, Aeromonas, Plesiomonas, Yersinia e Campylobacter. Os mecanismos de ação variam desde mecanismo invasivo gerando desinteria até aquelas que aumentam a secreção de líquidos dentro da luz intestinal gerando diarreia aquosa ${ }^{22}$.
O Staphylococcus aureus causa a patologia ao liberar uma toxina que é produzida durante a multiplicação, não existem dados que trazem referência a sua prevalência ${ }^{14}$. A Escherichia Coli trata-se do principal microrganismo componente da microbiota intestinal, no entanto essa espécie tem tendência de se modificar de organismo comensal para um patógeno oportunista colonizando outros sítios ${ }^{16}$. Essa capacidade torna tênue a delimitação entre ser saprofita ou patogênica ao ser humano. E.coli tem sua classificação baseada em mecanismos de patogenicidade. Seus sorotipos principais são: $E$. coli enteropatogênica (EPEC),E. coli enteropatogênica atípica (A-EPEC),E. coli enterotoxigênica (ETEC); iv) E. coli enterohemorrágica (EHEC).E. coli enteroinvasiva (EIEC), E. coli de adesão difusa (DAEC),E. coli enteroagregativa (EAEC). Várias dessas bactérias quando em desequilíbrio com a microbiota saprófita do trato gastrointestinal é capaz de provocar padrões diferentes de diarreia aguda ${ }^{23}$.

A OMS caracteriza a fisiopatologia da diarreia aguda em: diarreia aguda aquosa em que há perda de grande volume de líquidos corporais e desidratação. O mecanismo se baseia em uma secreção exacerbada de conteúdo aquoso para dentro da luz intestinal gerando diarreia em grande volume. O outro tipo é a Diarreia aguda com sangue (disenteria): a principal característica é a presença de sangue nas fezes e seu mecanismo fisipatológico e definido por uma invasão da parede intestinal (composta por enterócitos).Entre os possíveis patógenos intestinais encontrados o Staphylococcus aures costuma leva a um padrão de diarreia aquosa, na maioria das vezes. Por outro lado, as E. Coli varia conforme ao sorotipo. A E. coli enterohemorrágica (EHEC).E. coli enteroinvasiva (EIEC), por exemplo costumam gerar diarreia do tipo desinteria. No entanto, $E$. coli enteropatogênica (EPEC), E. coli enterotoxigênica (ETEC) possuem padrão de diarreia aquosa de grande volume ${ }^{26,27}$.

Esse estudo limitou-se a busca da diversidade de cepas e análise higiênico-sanitária, no entanto em continuação aos ensaios é importante que a verificação da resistência bacteriana aos antimicrobianos possa ser também avaliada para traçar um perfil de resistência na comunidade, exclusiva de ambientes de alimentação.

\section{CONCLUSÃO}

A partir dos dados apresentados no estudo fica evidente a necessidade de melhorias nos processos higiênicosanitários dos restaurantes, para que diminuía a contaminação alimentar. Apesar de não ter identificado, na maioria dos casos, cepas patogênicas ao trato gastrointestinal os achados nos remete a contaminação fecal podendo ser precedentes a cepas virulentas. É preciso criar alternativas dentro de processos educativos que possam esclarecer e oportunizar aos funcionários as melhores técnicas profiláticas antissépticas.

\section{REFERÊNCIAS}

1. Popkin BM. The nutrition transition: an overview of world patterns of change. Nutr Rev. 2004;62(7 Pt 2):S140-3. Acesso em 8 de abril de 2019 Disponível em: https://doi.org/10.1111/j.1753-4887.2004.tb00084.x S140-S143

2. Bezerra IN, Moreira TMV, Cavalcante JB, Souza AM, Sichieri R . Consumo de alimentos fora do lar no Brasil segundo locais de aquisição. Acesso em 
8 de abril de 2019 Disponível em :http://www.scielo.br/pdf/rsp/v51/pt 0034-8910-rsp-S151887872017051006750.pdf

3. Ma H, Huang J, Fuller F, Rozelle S. Getting rich and eating out: consumption of food away from home in Urban China. Can J Agric Econ. 2006;54(1):101-19. DOI:10.1111/j.1744-7976.2006.00040.x. Acesso em 8 de abril de 2019.Disponível em: http://www.scielo.br/scielo.php?script=sci nlinks\&ref=000105\&pid=S0 034-8910201300070000600017\&Ing=en

4. Perez-Rodríguez, F, Valero, A, Carrasco, E, García, RM, Zurera, G, 2008. Under- standing and modelling bacterial transfer to foods: a review. Trends Food Sci. Technol. 19, 131e144. Acesso em 8 de abril de 2019. Disponível em: https://doi.org/10.1016/j.tifs.2007.08.003

5. Souza, CVS, Azevedo PRM, Seabra LMJ, Food safety in Brazilian popular public restaurants: Food handlers' knowledge and practices. J Food Saf. 2018;38:e12512. Acesso em 8 de abril de 2019. Disponível em: https://www.ncbi.nlm.nih.gov/pmc/articles/PMC6221067/

6. Stull, JW, Peregrine, AS, Sargeant, JM, Weese, JS, 2013. Pet husbandry and infection control practices related to zoonotic disease risks in Ontario, Canada. BMC Publ. Health 13. Article 520. Acesso em 8 de abril de 2019.2 Disponível em: https://www.ncbi.nlm.nih.gov/pmc/articles/PMC3668296/

7. United States Health and Human Services (US HHS), 2014. Separate. Don't crosscontaminate. Acesso em 8 de abril de 2019. Disponível em: https://www.hhs.gov/

8. Doyle, M.P., Erickson, M.C., 2008. Summer meeting 2007ethe problems with fresh produce: an overview. J. Appl. Microbiol. 105, 317e330. Acesso em 9 de abril de 2019. Disponível em: https://www.ncbi.nlm.nih.gov/pubmed/18284485

9. Kolsin JM, Lopman BA, Payne DC, Wikswo ME, Dunn JR, Halasa NB, Hal AJ. Evaluating Previous Antibiotic Use as a Risk Factor for Acute Gastroenteritis Among Children in Davidson County, Tennessee, 2014 2015. J Pediatric Infect Dis Soc. 2018 Aug 17;7(3):e86-e91. Acesso em 9 de abri de $2019 . \quad$ Disponível em: https://www.ncbi.nlm.nih.gov/pubmed/29788403

10. Dos Santos AMP, Ferrari RG, Conte-Junior CA. Virulence Factors in Salmonella Typhimurium: The Sagacity of a Bacterium. Curr. Microbiol. 2018 May 21. Acesso em 9 de abril de 2019. Disponível em: https://www.ncbi.nlm.nih.gov/pubmed/29785632

11. Hiyoshi H, Tiffany CR, Bronner DN, Bäumler AJ. Typhoidal Salmonella serovars: ecological opportunity and the evolution of a new pathovar. FEMS Microbiol. Rev. 2018 Jul 01;42(4):527-541. Acesso em 9 de abril de 2019 . Disponível em: https://www.ncbi.nlm.nih.gov/pubmed/29790924

12. Meneguessi GM, Mossri RM, Segatto TCV, Reis PO, Morbimortalidade por doenças diarreicas em crianças menores de 10 anos no Distrito Federal, Brasil 2003 a 2012, Epidemiol. Serv. Saúde v.24 n.4 Brasília dez. 2015. Acesso em 10 abril de 2019. Disponível em http://scielo.iec.gov.br/scielo.php?script=sci arttext\&pid=S167949742015000400014

13. Souza, EL, Silva CA Sousa CP, Bacteriocins: molecules of fundamental impact on the microbial ecology and potential food biopreservatives. Brazilian Archives of Biology and Technology, v. 48, n. 4, p. 559-566, 2005. Acesso em 10 abril de 2019. Disponível em: http://www.scielo.br/pdf/\%0D/babt/v48n4/25718.pdf

14. Nataro JP, Kaper, J, Diarrheagenic Escherichia coli. Clinical Microbiology Reviews, v.11, p. 142-201, 1998. Acesso em 10 de abril de 2019. Disponível

http://www.scielo.br/scielo.php?script=sci_arttext\&pid=S1517 83822016000500003

15. Trabulsi LR, Keller R, Gomes TAT. Typical and atypical enteropathogenic Escherichia coli. Emerg Infect Dis 8:508-513, 2002. Acesso em 10 de abril de 2019. Disponível em https://www.ncbi.nlm.nih.gov/pmc/articles/PMC2732489/

16. Hart, CA, Winstanley, C. What makes a pathogen? Microbiology Today, v. 28 , p. 4-6, 2001. Acesso em 10 de abril de 2019. Disponível em: https://www.ncbi.nlm.nih.gov/pmc/articles/PMC2481411/

17. Levine, M. M. Escherichia coli that cause diarrhea: enterotoxigenic, enteropathogenic, enteroinvasive, enterohemorrhagic, and enteroadherent. Journal of Infectious Diseases, v. 155, p. 377-389, 1987. Acesso em 11 de abril de 2019. Disponível em: https://www.ncbi.nlm.nih.gov/pubmed/3543152

18. Jevsnik, $M$, Hlebec, $V$, Raspor, $\mathrm{P}$, . Consumers' awareness of food safety from shopping to eating. Food Control 19, 737e745, 2008. Acesso em 10 de abril de 2019 Disponível em https://ijae.springeropen.com/articles/10.1186/s41257-017-0007-6

19. Soussa $C P$, Dubreuil, JD,Distribution and expression of the ast $A$ gene (EAST1 toxin) in Escherichia coli and Salmonella. International Journal of Medical Microbiology, v. 291, p.15-20, 2001

20. Nascimento AR, Marques CMP. Avaliação microbiológica de saladas "in natura" oferecidas em restaurantes self-service de São Luiz, MA. Rev Hig Alim. 1998;12(57):41-4. Acesso em 10 de abri de 2019. Disponível em: https://www.researchgate.net/publication/325161259 DIVERSIDADE E PERFIL DE RESISTENCIA A ANTIBIOTICOS DE COLIFORMES ISOLA DOS DE SALADAS COMERCIALIZADAS EM RESTAURANTES SELFSERVICE/download

21. Predrag S; Branislava k, Miodrag $S$, Biljana S, Suzana $T$, Natasa M Tatjana $B$, Clinical importance and representation of toxigenic and nontoxigenic Clostridium difficilecultivated from stool samples of hospitalized patients, Braz. J. Microbiol. vol.43 no.1 São Paulo Jan./Mar. 2012. Acesso em 10 de abril de 2019. Disponível em: http://www.scielo.br/scielo.php?script=sci_arttext\&pid=S151783822012000100023

22. Isenberg, HD ,Garcia, LS; Isenberg. Clinical microbiology procedures handbook, 2011. Acessado em 10 de abril de 2019. Disponível em: https://www.ncbi.nlm.nih.gov/nlmcatalog/101528193

23. Ochoa TJ, Contreras CA. Enteropathogenic Escherichia coli infection in children. Curr Opin Infect Dis. 2011 Oct;24(5):478-3, Acessado em 10 de abril de 2019. Disponível em: http://scielo.iec.gov.br/scielo.php?script=sci arttext\&pid=S217662232016000200079

24. Marshall, BM, Ochieng DJ, Levy SB. Commensals: underappreciated reservoir of antibiotic. Microbe 2009 4:231-238. Acessado em 10 de abril de 2019.2 Disponível em:http://www.asmscience.org/content/journal/microbe/10.1128/mic robe.4.231.1

25. Sommer MOA, Dantas G, Church GM Functional characterization of the antibiotic resistance reservoir in the human microflora Science 2009 325, 1128- 1131. Acessado em 10 de abril de 2019. Disponível em: https://www.researchgate.net/publication/26773425 Sommer MOA Dantas G Church GM Functional characterization of the antibiotic resistance reservoir in the human microflora Science 325 1128$\underline{1131}$

26. Alves, NC, Odorizzi AC, Goulart, FC. Análise microbiológica de águas minerais e de água potável de abastecimento, Marília, SP. Revista Saúde Pública 2002, v. 36, n. 6, p. 749-751.Acessado em 10 de abril de 2019. Disponível em: http://dx.doi.org/10.1590/S0034-89102002000700014

27. American Public Health Association (APHA) Standard methods for the examination of water and waste water. 2005 21. ed. Washington, D.C.: American Public Health Association. Acessado em 10 de abril de 2019. Disponível https://www.scirp.org/(S(czeh2tfayw2orz553k1w0r45))/reference/Refe rencesPapers.aspx?ReferencelD $=1870039$ 